\title{
A Survey on Various Robotic Fish Models based on Oscillatory Motion
}

\author{
Anu Priya A. \\ PG Scholar, Dept. of CSE, \\ $\mathrm{KIT}$, Coimbatore, India
}

\author{
S. Raja Mohamed \\ Associate Professor, Dept. of \\ CSE, KIT, Coimbatore, India
}

\author{
P. Raviraj, $\mathrm{PhD}$ \\ Professor, Dept. of CSE, \\ KIT, Coimbatore, India
}

\begin{abstract}
Submerged robots are broadly acclimated in the acreage of amphibian development. The necessity for higher value and propulsive routine basically requires fish-like performance. Fish swim in an unusual motion such as ostraciiform. The Ostraciiform pond approach utilizes the caudal fin aerial to accomplish piscine propulsion with axis maneuverability. Various absolute automatic angle models based on oscillatory motion has been studied. Such as the sensors, actuators, accouterments and software used. Structures and abstracts acclimated in absolute angle robots and acceptation of alternative is reviewed. It helps in allotment of appropriate set of ambit to structural design of prototype fish for analysis purposes.
\end{abstract}

\section{Keywords}

Caudal fin, Computation Fluid Dynamics, AUV, Central pattern generator, Angle of Attack theory.

\section{INTRODUCTION}

Fish are effective swimmers. The design of their body structure is naturally refined for efficiency. The hydrodynamic efficiency of fish swimming is comparatively high than any other aquatic animals. Fish fins are the most distinctive feature of a fish, composed of bony spines protruding from the body with skin layer and joining them together. Caudal balances have no immediate association with the spine and are upheld by muscles. The caudal fin oscillation frequency enables the fishes travel faster. Fins located in distinct places on the fish serve for different locomotion such as swimming forward, backward, turning, rolling, and crawling. Fish swim either by Body and/or Caudal Fin (BCF) actions or using Median and/or Paired Fin (MPF) driving force. There are two types of motion oscillation and undulation employed for thrust generation of the fish to move further. Oscillation motion uses the paired fins, pectorals and pelvic, to generate highly maneuverable movement. Body forms are different with regard to the difference in oscillation and undulation. Wavering Wing gets the great execution, when a elite tail balance in hydrodynamics, a streamlined body and a slim peduncle are joined. The body with few drag and solid propulsive power by the tail balance acquire fast swimming. Underwater robots are widely used in the fields of ocean development, ocean investigation, and marine environmental protection. The underwater robots for fishlike swimming mechanisms incorporate the autonomous under water vehicle. Ostraciidae fish have unbending boxlike bodies made out of combined scales with openings for eyes, mouth, gills, rear-end, and blades[1].

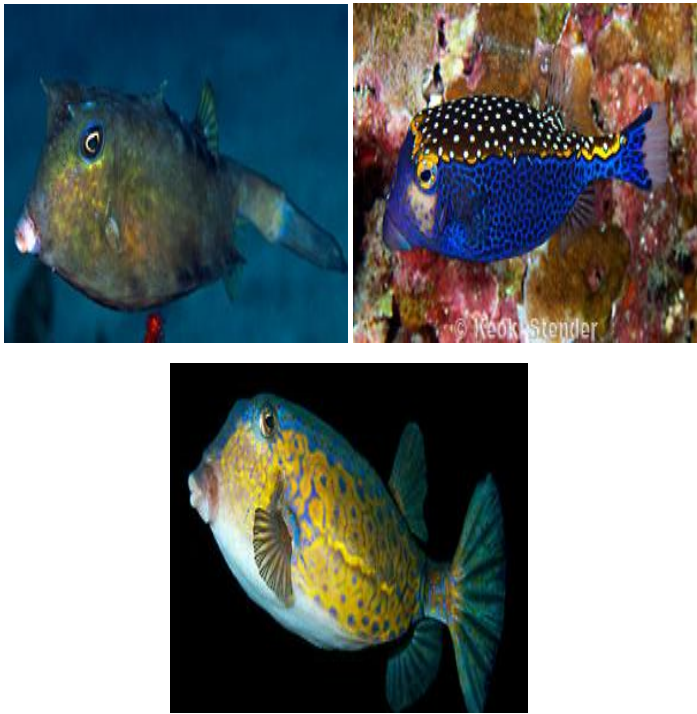

Figure 1. Pictures of the different existing Ostraciidae fish a) lactoria-diaphana b) ostracion-meleagris c) ostracion-cubicus-2 [16]

The family incorporates the genera Lactoria, Ostracion, and Tetrosomus. Lactoria diaphana[16] (ROUNDBELLY COWFISH) Ostracion meleagris [16] (SPOTTED BOXFISH) Lactophrys triqueter (SMOOTH TRUNKFISH) [16] are some types of Ostraciidae fishes with oscillating swimming behavior shown in Figure-1.

\section{BACKGROUND}

Biomimetric submerged vehicle has included the consideration of numerous analysts for settling crisis in the engineering field. Bio-inspired fish robots are regarded as next generation of AUV for oceanic tasks such as armed supervision, biological researches. Figure-2 shows a classification scheme of fish locomotion mechanisms. It was originally presented in [11] and was modified in [14].The three main swimming styles are characterized by undulatory body motion, undulatory fin motion, and oscillatory fin motion. The main classification of fish locomotion is one proposed by Breder [13] that has two styles of swimming body and/or caudal fin (BCF) locomotion, and the other is median and/or paired fin (MPF) locomotion [11]. The difference between oscillatory and undulatory is the number of waves passed down the body and fin. When number of waves is less then it appears to be oscillating plate and this mode is called oscillatory. In other way if the wave number is large then it comes under undulatory. The category of undulation and oscillation is based on fin kinematics of the species. Oscillatory swimmers have better and efficient lift performance compared to undulatory [12]. 


\section{REVIEW OF FISH ROBOTS}

Fish are able to move efficiently due to their body shape, fin form and kinematic [16]. The aerodynamic shape of fish body reduces drag and unstable flow while kinematic produces thrust for progress. Natural mechanism cannot be applied precisely to marine vessels to produce good practical results. Nevertheless, natural mechanisms of fish locomotion are an inspiration for the development of aquatic vessels driving force system.

Underwater fish robots are widely used in ocean development, ocean investigations, marine and environmental monitoring and protection. In order to develop high-performance, intelligent underwater robots, a fish robotics study was undertaken in 1999 at the Ship Research Institute, part of the Japan Ministry of Transportation in Tokyo Japan [9]. Locomotion of fish are various and interesting they have many specialized modes of movement. Each fin on a fish is intended to perform a specific function For example; an eel swims waving the whole of its body and is highly adapted to an enclosed environment. A flat fish, on the other hand, swims by waving long fins in special patterns, allowing it to hover, backup or turn quickly in any direction.

Development of robotic fish propulsion consider several aspects such as the shape of the robot, pattern of movement, hydro-dynamics, and control system, location of the machine, mechanical properties and material properties [13, 14]. In order to measure basic performance of the fish robot, several experimental fish robots have been designed and tested. Most existing fish robots are inspired by the real fish locomotion. The National Marine Research Institute in Japan is working on

multiple projects, including maneuvering, swimming performance and modular robotics for water. Their PF series is described in the table below. In order to study the up-down motion of a small fish robot, PF 200 the Prototype Fish Robot was designed and built. Prototype Fish Robot, PF-300 was designed and built to optimize turning performance. Next is the PF 550 which is designed with special mechanism of rotating shaft at the tail to quick up-down motion of the robot. The University of California built a biomimetic micro underwater vehicle in 2005 with oscillating fin propulsion named as Boxfish robot. Its length is only $12 \mathrm{~mm}$ and its weight is $1 \mathrm{~g}$. The locomotion of box fish robot replicates the real box fish swimming behavior. The electromechanical device with rigid body propelled by an oscillating tail fin and steered by a pair of autonomous side fins. The oscillating motions of the fins are controlled by PZT bimorph actuators driving four-bar mechanisms for motion amplification.

The PF-200 adapted 'movement of weight' mechanism. The mechanism brings inclinations of the fish robot, and it has the up-down motion with the thrust force of a tail fin. A weight is located in a head, and it moves to the front and the rear. A servomotor for the tail fin and another servomotor for the weight are located in a body. A microcomputer drives the servomotor with a given pattern repeatedly. Floating force is adjusted for up-down motion of the fish robot.

Basic speed performance of PF 300 is measured in straight forward propulsion. Straight-line speed is measured while changing frequency and amplitude. The maximum speed of the PF-300 was about $0.2 \mathrm{~m} / \mathrm{s}$ at $\mathrm{Ka}=0.6, \mathrm{f}=2.3 \mathrm{~Hz}$, and $\mathrm{B}=20$ degrees. The speed per the body length is not higher than any former model fish robots. PF-300 was designed and aimed only for high turning performance.

The Prototype Fish Robot, PF-550 is designed for quick up -down motion of a fish robot. The PF-550 is fat fish robot; the body of boxfish like PF-550 has a very rigid body which is not flexible. It does not have high swimming speed. But with special mechanism, which rotates the tail part has quick up-down motion. Shaft attached to the caudal fin helps in this rotation.

The Table-1 summarizes some of the robotic fishes which perform oscillatory motion with in-built hardware features and their imitating real fishes with oscillatory swimming mode.

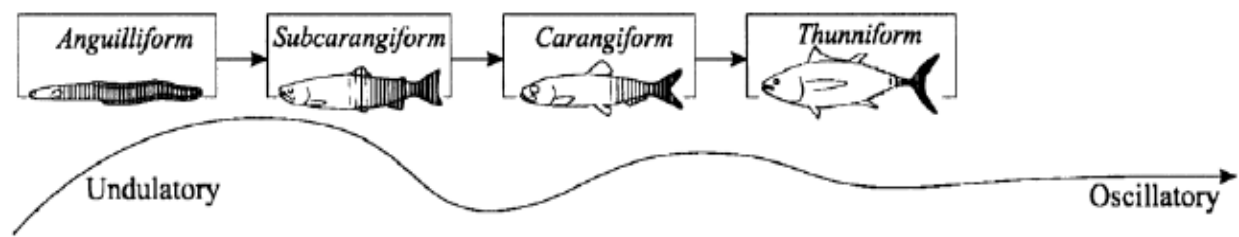

(a)

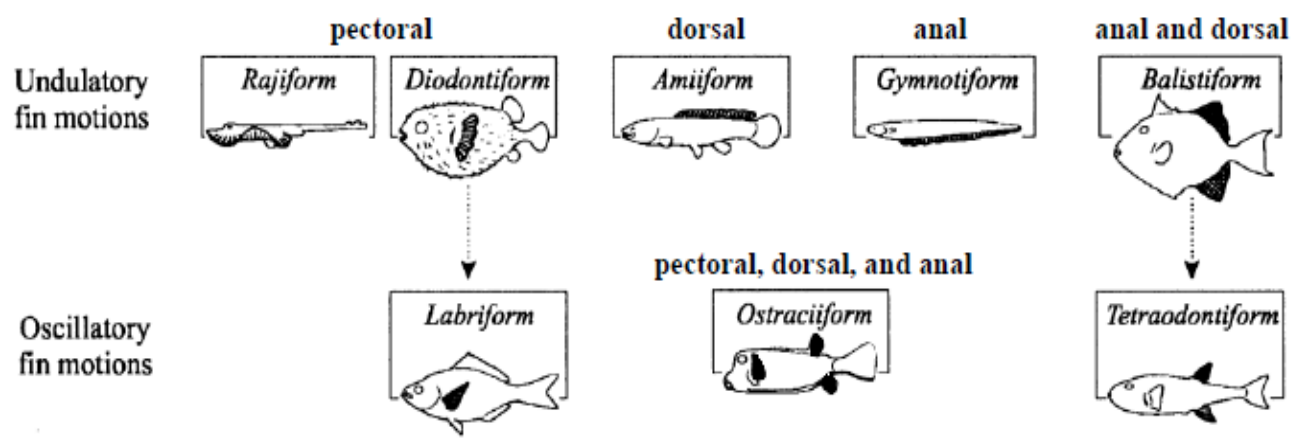

(b)

Figure 2. (a) BCF (b) MPF Fish classification based on swimming styles originally appeared in [11] and modified in [14] 
Table 1.Summary of Robotic Fishes

\begin{tabular}{|c|c|c|c|c|}
\hline Name & Figure & Imitating Fish & Swimming mode & Features \\
\hline Boxfish robot & & Box Fish & Oscillatory motion & $\begin{array}{l}\text { Micro vehicle controlled by } \\
\text { PZT bimorph actuators, } 2 \\
\text { Length: } 12 \mathrm{~mm} \\
\text { weight: } 1 \mathrm{~g}\end{array}$ \\
\hline PF-200 & & Ostracion-cubicus-2. & Oscillatory motion & $\begin{array}{l}\text { Driven by DC servo motor } \\
\text { for tail fin and another } \\
\text { servomotor for weight } \\
\text { located in body. } \\
\text { Microcomputer The PF- } 200 \\
\text { has } 543.4 \text { gf of weight on } \\
\text { air. Swims about } 35 \mathrm{~cm} \text { deep } \\
\text { in } 15 \mathrm{~s} \text {. Length: } 0.3 \mathrm{~m}\end{array}$ \\
\hline PF-300 & & Sea Bream fish & Oscillatory motion & $\begin{array}{l}\text { A radio control (R/C) } \\
\text { receiver is located in a } \\
\text { head. A battery and one } \\
\text { servomotor (servo) for } \\
\text { moving the tail. To } \\
\text { waterproof the link } \\
\text { mechanism, rubber boots } \\
\text { are used. Maxi speed: } 0.2 \\
\mathrm{~m} / \mathrm{s} \text {, quick turn : } 75 \mathrm{~mm} \text { in } \\
10 \mathrm{~s} \text { at an oscillation of } 2.2 \\
\text { Hz. Length: } 0.34 \mathrm{~m}\end{array}$ \\
\hline PF-550 & & Ostracion-meleagris & Oscillatory motion & $\begin{array}{l}\text { Servomotor in the tail } \\
\text { peduncle. R/C receiver. } \\
\text { The body covers and the } \\
\text { tail peduncle cover are } \\
\text { made by FRP material. } \\
\text { Length:0.6m }\end{array}$ \\
\hline
\end{tabular}

\section{EXISTING WORK}

Table 2. List of few existing papers based on bio-inspired robotic fishes and robotic fishes with oscillating fin

\begin{tabular}{|c|l|l|}
\hline Case No & \multicolumn{1}{|c|}{ Title } & \multicolumn{1}{|c|}{ Authors } \\
\hline Case 1 & $\begin{array}{l}|c| \\
\text { Microautonomous Robotic Ostraciiform (MARCO): } \\
\text { Hydrodynamics, Design, and Fabrication }\end{array}$ & $\begin{array}{l}\text { Parasar Kodati, Jonathan Hinkle, Aaron } \\
\text { Winn, and Xinyan Deng, 2008. }\end{array}$ \\
\hline Case 2 & $\begin{array}{l}\text { A Bionic Fish Propulsive Mechanism with Caudal Fin } \\
\text { Oscillating in Variable Direction Based on Linear } \\
\text { Hypocycloid }\end{array}$ & $\begin{array}{l}\text { Shu-Yan Wang, Zhujun, Xin-guo } \\
\text { Wang, Qinfeng Li, 2015. }\end{array}$ \\
\hline Case 3 & $\begin{array}{l}\text { BoxyBot: a swimming and crawling fish robot } \\
\text { controlled by a central pattern generator }\end{array}$ & $\begin{array}{l}\text { Daisy Lachat, Alessandro Crespi, and } \\
\text { Auke Jan Ijspeert,2013 }\end{array}$ \\
\hline Case 4 & $\begin{array}{l}\text { A Framework for Biomimetic Robot Fish's Design and } \\
\text { Its Realization }\end{array}$ & $\begin{array}{l}\text { Junzhi Yu, Long Wang, and Min Tan, } \\
\text { 2005. }\end{array}$ \\
\hline Case 5 & $\begin{array}{l}\text { Dynamic Modeling of an Ostraciiform Robotic Fish } \\
\text { Based on Angle of Attack Theory }\end{array}$ & $\begin{array}{l}\text { Wei Wang, Guangming Xie and Hong } \\
\text { Shi, 2014. }\end{array}$ \\
\hline Case 6 & $\begin{array}{l}\text { Biomimetic Micro Underwater Vehicle with } \\
\text { Oscillating Fin Propulsion: System Design and Force } \\
\text { Measurement }\end{array}$ & $\begin{array}{l}\text { Xinyan Deng and Srinath Avadhanula } \\
\text { 2005. }\end{array}$ \\
\hline
\end{tabular}




\section{Case 1:}

Tail balance hydrodynamic has been explored experimentally utilizing automated flapper instrument to land at a caudal blade shape with ideal shape prompted adaptability. A model has been developed that illustrates the hydrodynamics of an oscillating rigid fin in [11]. 3-D CAD programming to assemble body shapes. Servo engine with inherent input rather than dc engine is implied. The paper achieves the maneuverability of little scale numerous balance submerged framework like box fish and a self revising instrument. The hydrodynamic force bearing of appendage fin has been modeled application an aggregate of quasi-steady lift generation, and empirically found drag and added accumulation effects. Fluid flow simulations on 3-D CAD models of boxfish-like shapes were acclimated to access the outer shape of the MUV. The propulsion and action of the MUV is achieved by the appendage fin and two 2 DOF ancillary fins.

Case 2:

The caudal fin is the most effective motion in fishes. Taking into consideration the two types of fishes Tuna and Dolphin, Tuna oscillates its caudal fin in horizontal direction but the dolphin flaps the caudal fin in vertical direction. Both the movements produce a forward thrust for the fish to move forward. Models of these two types of swimming are compared. A bionic propulsive of caudal fin composing of planetary set and Spherical linkage based on linear hypocycloid was designed. Kinematics simulation in MATLAB was conducted. The linear hypocycloid mechanism fits the propulsion properties such as both tuna and dolphin. The design of bionic propulsive mechanism realizes the maneuverability by changing the oscillation position.

Case 3:

A novel fish robot capable of swimming and crawling is been designed and studied. It is composed of DC motors and three actuated fins with two pectoral fins and one caudal tail fin. The design is inspired from oscillatory motion box fish. The control unit of the robot is constructed using central pattern generator. The sensory input triggers the movement of the fish robot such as moving forward, moving backward, moving upwards and downwards. The concept of CPG is applied to control the novel fish robot. Central pattern generator (CPG) executed as an arrangement of coupled nonlinear oscillators. The pace of motion can be balanced by gradually increasing both the frequency and/or amplitude parameters of the CFG.

\section{Case 4:}

The design and motion control of radio- controlled, multilink and free swimming biomimetic robotic fish based on kinematic propulsive model is developed. By ichthyologic theory multiple linked robot fish with flexible posterior body and oscillating tail fin is been designed and tested to the robot. By changing the oscillating frequency and oscillating amplitude the speed of the swimming fish can be varied. The robot fish consists of control unit, sensor unit, dc motors and accessories. Several kinds of robot fish prototype with different functions were designed and built to validate the framework for Biomimetic Robot Fish's [9].

\section{Case 5:}

A AoA-based dynamic model for a CPG controlled ostraciiform robotic fish, which, in conjunction with the CPG controller, is able to predict mechanical behaviors of the robot and guide the search for CPG parameters and gaits optimization of the robot[14]. Angle of Attack Theory is used to explore the relationship between swimming efficiency. Dynamic model for an ostraciiform robotic fish based on AOA and lagrangian equations were developed. Comparing other dynamic models of robotic fishes the AOA based model can see the sights between hydrodynamic forces and the angle of attack of fins. CPG controller deals with all redundancies and transitions on receiving control signals. They produce signals to the joint angle which actuated the multi rigid robotic body system.

\section{Case 6:}

The locomotion on real box fish was investigated to replicate the boxfish robot. An electromechanical device is designed and tested with rigid body and oscillating tail. Oscillating motion of the caudal fin is controlled by PZT bimorph actuators [15]. The boxfish robot is capable of autonomous swimming. It can be used in undersea pipe line inspection, under water ship-wreck exploration. The electromechanical device has mass of $1 \mathrm{~g}$, body length of $10 \mathrm{~mm}$, tail fin of $10 \mathrm{~mm}$ with oscillating frequency of around $5 \mathrm{~Hz}$. The device consists of the locomotory unit, the sensory system unit, the power supply unit, the communications unit and the control unit. The locomotory unit controls the oscillatory fin propulsion for moving forward. The sensory system unit it detects the objects around and motion detection.

The power supply unit produces the necessary electric energy to power the fin. The communication unit helps the robot to communicate with other robot. Control unit controls the entire mechanism in box fish robot and plans the correct trajectory for desired movement Table-3 Lists out some of the critical parameters that are identified from case1, case 2 , case 3 , case 4, case 5, case 6. Critical parameters such as fish length weight, sensors, pressure, actuators and the hardware and software used to design and test the fish like robot.

Table 3. Critical parameters identified from the existing papers discussed above

\begin{tabular}{|c|c|c|c|c|c|c|}
\hline Sl. No. & $\begin{array}{l}\text { Fish Length/ } \\
\text { Weight }\end{array}$ & & & Pressure & Actuator & $\begin{array}{l}\text { Hardware/ } \\
\text { Software }\end{array}$ \\
\hline 1 & $\begin{array}{l}15 \mathrm{~cm} \text { in length, } \\
490 \mathrm{gm} \text { in weight }\end{array}$ & $\begin{array}{l}\text { Fixed } \\
\text { based } \\
\text { sensor }\end{array}$ & $\begin{array}{l}\text { beam } \\
\text { force }\end{array}$ & $\begin{array}{l}\text { Pressure drag } \\
\text { increases }\end{array}$ & $\begin{array}{l}\text { Servo motor with built in } \\
\text { feedback were used in } \\
\text { place of DC motor. }\end{array}$ & $\begin{array}{l}\text { PID controller were } \\
\text { used to run the } \\
\text { motor at a high level } \\
\text { of precision. } \\
\text { (CAD/CAE) tool } \\
\text { such a solid } \\
\text { modeling software } \\
\text { and fluid-flow }\end{array}$ \\
\hline
\end{tabular}




\begin{tabular}{|c|c|c|c|c|c|}
\hline & & & & & simulation software. \\
\hline 2 & $\begin{array}{l}\text { Fish length } 588 \mathrm{~m} \text {, } \\
\text { Weight }=2.79 \mathrm{~g}\end{array}$ & - & $0.09-0.62 \mathrm{~m} / \mathrm{s}$ & - & $\begin{array}{l}\text { Servo Toeing } \\
\text { system, } 4000 \text { watt } \\
\text { AC motor, controller } \\
\text { Area } \\
\text { Network(CAN) bus. }\end{array}$ \\
\hline 3 & Length $25 \mathrm{~cm}$. & $\begin{array}{l}\text { Light and water } \\
\text { sensors }\end{array}$ & - & PZT bimorph actuators & $\begin{array}{lr}\text { Solid } & \text { works } \\
\text { software.3D } & \text { printer } \\
\text { power } \quad \text { converter } \\
\text { PCB. }\end{array}$ \\
\hline 4 & Length $450 \mathrm{~m}$ & $\begin{array}{l}\text { Sensor unit } \\
\text { (infrared, visual, } \\
\text { ultrasonic) }\end{array}$ & $\begin{array}{l}\text { Velocity is - } \\
0.049 \mathrm{~m} / \mathrm{s}\end{array}$ & $\begin{array}{l}\text { Discrete control method is } \\
\text { employed to actuate the } \\
\text { pectoral fin. }\end{array}$ & $\begin{array}{l}\text { DC servomotor, } \\
\text { wireless receiver. }\end{array}$ \\
\hline 5 & Length $100 \mathrm{~mm}$ & $\begin{array}{lr}\text { Pressure } & \text { sensor } \\
\text { array } & \text { and } \\
\text { infrared } & \text { sensor }\end{array}$ & - & - & $\begin{array}{lr}\text { Vision } & \text { tracking } \\
\text { software, } & \text { Servo } \\
\text { motor } & \end{array}$ \\
\hline 6 & Length $10 \mathrm{~mm}$ & $\begin{array}{l}\text { 2-DOF linear } \\
\text { force sensor }\end{array}$ & - & PZT bimorph actuators & $\begin{array}{l}\text { CAD tool such a } \\
\text { solid modeling } \\
\text { software and fluid- } \\
\text { flow simulation } \\
\text { software. }\end{array}$ \\
\hline
\end{tabular}

\section{CONCLUSION}

Oscillatory motion is a harmonic one that depends upon the speed at which tail fin swings. Oscillatory motion is generally implemented using servomotors but at the same time actuators are also used to reduce the overload of power system. This motion is implemented using simple servo motors connected serially depending upon the length of fish body. But it is really effective when 2 or 3 servomotors to the maximum exploded in case 2 and case 4 . It operates based on angular difference between parts of the fish body separated into small segments leading to sub-carangiform motion but using single servo motor ensures perfect oscillatory motion. Similarly PID controllers were also used as actuators to generate oscillating motion leading to more power consumption than conventional sensors. When the robot fish has additional sensing units such as sensors for application specific usage requires more energy along with controlling servo motors so it is highly challenging task while designing robot fish to choose between varieties of actuators to preserve energy. In recent days SMA which is capable of working with very minimal power but costing more in terms of material and design. As far as orcillatory motion is concerned with reference to the survey across 6 different cases using single servo motor seems to be the best fit as it prolongs the life and efficiency of robotic fish.

To improve the performance of robotic fish the following key parameters such as aspect ratio, taper ratio, sweep ratio are identified during analysis using bht. The models can be simulated and then prototypes can be designed in considerable amount of time depending upon the type of application requirement. Already applications such as oil spill detection, marine life safety, pollution detection are the key areas in which robotic fish are widely used.

\section{REFERENCES}

[1] Blake, R. W.2004. Fish functional design and swimming performance. Journal of fish biology, 65(5): 1193-1222.

[2] C. C. Lindsey.1978. Form, function and locomotory habits in fish in Fish Physiology Volume VII:
Locomotion, W. S. Hoar and D. J. Randall, Eds.. New York: Academic, pp. 1-100.

[3] C.M. Breder. 1926. The locomotion of fishes Zoologica, vol. 4, pp. 159-256

[4] Daisy Lachat, Alessandro Crespi, and Auke Jan Ijspeert. 2013. BoxyBot: a swimming and crawling fish robot controlled by a central pattern generator. Swiss Federal Institute of Technology, Lausanne (EPFL) Station 14, CH-1015 Lausanne, Switzerland.

[5] Dr David M. Lane, Michael Sfakiotakis, Dr. J. Bruce C. Davies.1999. Review of Fish Swimming Modes for Aquatic Locomotion. IEEE Journal of oceanic Engineering, vol.24,No.2,pp.237-252.

[6] J. E. Colgate and K. M. Lynch. 2004. Mechanics and control of swimming: A review.IEEE J. Ocean. Eng., vol. 29, no. 3, pp. 660-673.

[7] JD Geder, R Ramamurti, M Pruessner, J Palmisano Oceans-San Diego.Maneuvering performance of a four-fin bio-inspired UUV.

[8] JS Palmisano,R Ramamurti, JD Geder, M Pruessner. 2007. How to maximize pectoral fin efficiency by control of flapping frequency and amplitude. WC Sandberg,18th International Symposium on Unmanned Untethered Submersible Technology.

[9] Junzhi Yu, Long Wang, and Min Tan. 2005. A Framework for Biomimetic Robot Fish's Design and Its Realization. American Control Conference June 810, 2005. Portland, OR, USA

[10] Low K. H., \& Willy, A.2006. Biomimetic motion planning of an undulating robotic fish fin. Journal of Vibration and Control, 12(12): 1337-1359.

[11] Parasar Kodati, Jonathan Hinkle, Aaron Winn, and Xinyan.2008. Microautonomous Robotic Ostraciiform (MARCO): Hydrodynamics, Design, and Fabrication. Deng. IEEE TRANSACTIONS ON ROBOTICS, VOL. 24, NO. 1. 
[12] S. Raja Mohamed S. Raja mohamed and P. Raviraj. 2015. Bio-Inspired Swimming Techniques for Robotic Fish using Flow and Pressure Sensing Mechanism (Computational Bio-Mimetic). Indian Journal of Science and Technology, Vol 8(24), IPL0317.

[13] Shu-Yan Wang, Zhujun, Xin-guo Wang, Qinfeng Li. 2015. A Bionic Fish Propulsive Mechanism with Caudal Fin Oscillating in Variable Direction Based on Linear Hypocycloid.The 14th IFToMM World Congress, Taipei, TaiwanDOINumber: 10.6567/IFToMM.14TH.WC.OS1.005.

[14] Wei Wang, Guangming Xie and Hong Shi. 2014. Dynamic Modeling of an Ostraciiform Robotic Fish Based on Angle of AttackTheory http://www.researchgate.net/publication/264436142 DOI: 10.1109/IJCNN.2014.6889881.
[15] Xinyan Deng and Srinath Avadhanula. 2005. Biomimetic Micro Underwater Vehicle with Oscillating Fin Propulsion: System Design and Force Measurement" International Conference on Robotics and Automation Barcelona, Spain.

[16] Zhang D., Low, K. H., Xie, H., \& Shen, L.2009. Advances and Trends of Bionic Underwater Propulsors. IEEE WRI Global Congress on Intelligent Systems, 1: 13-19.

[17] http://www.fishbase.org/identification/SpeciesList.php ?famcode $=446 \&$ areacode

[18] https://www.nmri.go.jp/eng/khirata/fish/experiment/ex perimente.htm 